\title{
An Empirical Case Study on College English Academic Writing with Project-based Learning Model
}

\author{
Li Jiang ${ }^{1, a}$ \\ ${ }^{1}$ Nanchang Institute of Science and Technology, 330108 \\ ajianglijx@126.com
}

Keywords: Project-based learning; College English academic writing; Teaching empirical study

Abstract. This paper is a practical case study on college English academic writing teaching with project-based learning model. The mostly discussed is the necessity and availability of newly developed project-based learning model in the college English academic writing teaching.

\section{Introduction}

Chinese higher educational globalization process is advancing in accordance with international economic growth in recent years. Teaching method of college English in our country is steering to a more diversified system of teaching direction, pattern and content to strengthen Chinese students' comprehensive abilities in English using ${ }^{[1]}$. Speaking of students' comprehensive abilities in English using, academic English writing forms an important foundation, which is why we need an initiative of project-based learning model and weighs a lot in our higher educational globalization process.

\section{Project-based Learning Model}

\section{Definition of project-based learning model}

Project-based learning model is a systematically organized learning mode which requires students autonomously design their own study tasks on one topic and accomplish them, during which they can pick up a skill or so and relevant knowledge. This practices students to take fully advantage of study resources around and enables them to communicate with each other and to brainstorm together. Here are some features about it: (1) this mode integrates teaching and learning together ${ }^{[2]}$; (2) it emphasizes more on the basic skills and knowledge; (3) it is more used in complex situation where deeper study and resolution should be drawn; (4) students' autonomy and creativity can be further developed.

\section{Project-based learning model and college English academic writing}

What underlies academic English writing is project-based learning mode. The authenticity and importance of this model benefits academic English study a lot, and in turn, the realization and effectiveness of academic English carries the study results, and then we can tell a close logical relation between project-oriented learning model and academic English. Being a key issue in academic English, academic writing in English is also the primary purpose. Combination of project-based learning and academic English writing can provide itself as an effective way in college English writing teaching.

\section{Study Design and Practice}

\section{Study target}

This study covers two non-English major classes in their first grade about the same English learning level from a normal college, choosing one from them as the experimental class and the other the comparing class. 42 students from the experimental class experience the project-based learning model in academic English writing while 40 students in comparing class are placed with traditional teaching method. 


\section{Study tools}

Tests are conducted at the beginning and end of one school term with this study going the whole term. Collected writing contexts of both tests are evaluated by the standard CET-4. Stats from the study are further calculated by formula $\overline{\mathrm{x}} \pm \mathrm{s}$ ( $\overline{\mathrm{x}}$ stands for average number; s stands for standard deviation) and examined by $t$ which means the independent sample.

\section{Study method}

The whole design is set on the requirements for freshmen combing college English writing with project-based learning model. Students are required to complete three project-based tasks covering categories like e-mail, posters, online pages and descriptions within 14 weeks. Under the guidance of tutors, the specific routine can be divided into steps including topic choosing, preparation, implementation, result demonstration and afterwards evaluation. In the study, comparing class adopted traditional teaching method that tutors mainly talk about grammar and writing issues and assign homework which students need to finish and hand them over to teachers for modification and credits. The experimental class, on the other hand, employs the project-based learning model which requires students to do consulting things in literature work and ground research in several study groups. When the huge consulting work is done, they are meant to get together reorganizing these materials and completing the final article. The last part of it is to discuss their works among groups and teachers to draw collective reviews.

\section{Result analysis}

Results are drawn on students' final scores. Table 1 shows a comparison of the beginning and end score in the experimental class, which tells us after the research the experimental class acquires a higher score than the comparing class and the collected data remains worth in statistics aspect (P $<0.05$ ). It is known that these two class average scores hold at the same level appearing no statistics differences after conducting T-test on samples just before the research. Turns out, the comparing class with traditional teaching methods appears no advance in students' academic English writing ability. On the contrary, students in the experimental class with project-based learning model have gained great progress in their academic English writing.

Table 1 article evaluation results in different stages of two classes (scores)

\begin{tabular}{|c|c|c|}
\hline & before & after \\
\hline Experimental class (42) & $75.49 \pm 2.73$ & $84.76 \pm 2.54$ \\
\hline Comparing class (40) & $77.01 \pm 2.84$ & $77.12 \pm 2.38$ \\
\hline T value & 2.471 & 14.038 \\
\hline P value & 0.016 & 0.000 \\
\hline
\end{tabular}

Reasons for such differences are as below. First, students in experimental class are required to do consulting things in literature work and ground research in several study groups. When the huge consulting work is done, they are meant to get together reorganizing these materials and completing the final article. Mutual communication and brainstorm are called on in this process. This means the article equips more reality, professional skills and authenticities due to students' positive deep thinking, research, consultation and cooperation, which adds more elements, deeper thoughts and more appealing to the final paper ${ }^{[4]}$. Second, when works done, students in experimental class will get a deeper review and discussion among the whole class. By raising advices and opinions, students will exchange with each other, sum up experience and get better together. This makes the space of their articles numerous, mistakes less and sentential form variation more diversified. The atmosphere in comparing class appears quite desolate that only students finish their works on their free thoughts without systematically thinking, research and close communication with each other, which results their works appearing thinner, duller and more boring. 


\section{Conclusion}

Project-based learning model refers to a systematically organized learning mode of project as the whole outline, group cooperation and automatic study as main method and result as the final target. If one wants to complete an academic writing, he needs to collect useful materials, integrate relevant information and add his own thoughts in the article. Finishing the article by oneself is just the first step. Afterwards, teachers and students will gather together to exchange their thoughts and reviews to prompt students correct their mistakes and absorb the good ones. This model stimulates their interests and motives in academic English writing by creating real missions attracting students to immerse into the academic English study. Document consulting and communication raises students' reading and writing abilities on one hand, field research, general inspection and reorganizing materials exercise students' automatic study, cooperation and comprehensive practical abilities on the other hand. Combining these two aspects together can realize a development in students' self-thinking awareness and comprehensive performance. In a word, the project-based learning model plays a crucial role in students' academic English writing ability, as well as a worthy instrument for overall quality improvement, which should be widely used across the ground.

\section{Reference}

[1] Chen Wang. Potential Problems in English Teaching with Project-based Teaching Model [J]. Du Shi Jia Jiao, 2015, 12(7):31-31.

[2] Xiaohui Zhu, Yang Luo, Shiyu Liu. Practical Research of Project-based Learning Model in Academic English Writing [J]. Journal of Changchun University of Science and Technology, 2015, 28(8):151-156.

[3] Feie Peng. Study Evaluation Basing on Project_—A Case Study on English Project-based [J]. Information Technology Education, 2014, 17(6):18-22.

[4] Yuxiu Huo. Empirical Case Study in English Teaching with Project-based Learning Model[J]. Journal of Language and Literature Studies, 2013, 22(10):90-91. 